\title{
THE ELECTRICAL CONDUCTIVITY OF COMMERCIAL COPPER
}

\author{
By F. A. Wolff and J. H. Dellinger
}

\section{CONTENTS}

I. Introduction. . . . . . . . . . . . . . . . . . . . . .

I. Notes on table of standard values............... I04

2. Table I. Standard values ...................... 105

3. Scope of this investigation ....................... 106

II. The experimental work ......................... 108

I. The Thomson bridge method ................. Io 8

2. The apparatus ........................ III

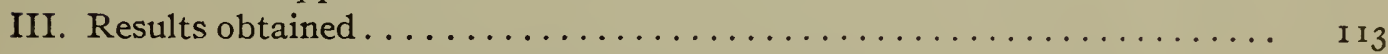

I. Resistivity of commercial copper................... II 3

2. Copper of especially high conductivity ............... II 4

3. Data on hard-drawn aluminum .................... II5

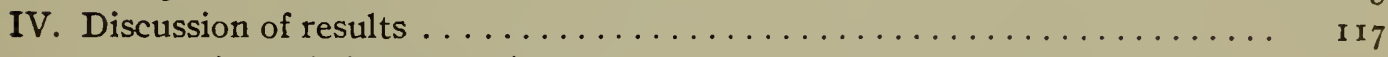

I. Annealed copper wires....................... I 7

(a) Summary of above data................... ${ }_{1} 17$

(b) Summary of data from American Brass Company..... II 7

2. Hard-drawn copper wires . . . . . . . . . .

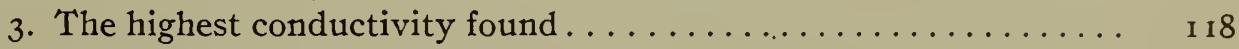

4. Aluminum ................................ I

5. Temperature coefficient of copper................ II9

V. Conclusions . . . . . . . . . I I

I. Best value for the resistivity of annealed copper......... I2I

2. Density of copper.......................... I 22

3. Temperature coefficient of annealed and of hard-drawn copper.. 122

4. Percent conductivity ............................ 122

5. Data for use in wire tables ...................... 123

6. The expression of resistivity in ohms per meter-gram ........ I 23

7. Desirability of an international standard of copper conductivity.. I 24

VI. Summary ................................. I 25 


\section{INTRODUCTION}

The values in use for the conductivity, resistivity, and temperature coefficient of copper vary considerably. The standard values for annealed copper as used by various institutions in different countries are given in Table I, on the adjoining page:

\section{NOTES ON TABLE OF STANDARD VALUES}

The values given in the table for the various temperatures are computed from the values at the particular standard temperature, which are indicated by heavy-faced type. In each column the temperature coefficient of that column is used in computing the resistivity in ohms per meter-gram at the various temperatures.

The data for the English values (col. I) were obtained from the report of the Engineering Standards Committee, August, I904.

The values for "Normal Kupfer" (col. 2) were computed from the data given in E. T. Z. I 7, 402; I896, and "Normalien, etc., d. Verbandes Deutscher Elektrotechniker," I907, page 68. The value for conductivity given was reduced to meter-gram resistivity by the use of the density given as standard, 8.9I. The values in column 3 are calculated on the assumption of a density of 8.89. The German "Normal Kupfer" is in use also in Austria.

The Matthiessen value as computed by Lindeck (col. 4) is based on the data given in C. Hering's "Conversion Tables". (John Wiley and Sons, N. Y., 1904), page ro4, and was reduced to the meter-gram basis on the assumption of the density, 8.89, and Matthiessen's temperature formula.

The values which were adopted by the American Institute of Electrical Engineers in 1893 are given in col. 5. They were derived from the results Matthiessen published in 1862 . (The $0^{\circ}$ and $20^{\circ}$ meter-gram values are equivalent to 1.59425 and I.72128 micro-ohms per $\mathrm{cm}$ cube, respectively). In I908 Matthiessen's temperature formula was dropped by the A. I. E. E. and the linear temperature coefficient of 0.0042 at $\mathrm{O}^{\circ} \mathrm{C}$ was adopted (col. 6); this vitiated the old wire table of the Institute; and, as the $0^{\circ}$ value of the resistivity was retained, the resistivity at all other temperatures was altered. The $20^{\circ}$ value of the resistivity was retained by the Bureau of Standards (since the measurements of Matthiessen at $20^{\circ} \mathrm{C}$ were probably at least as 


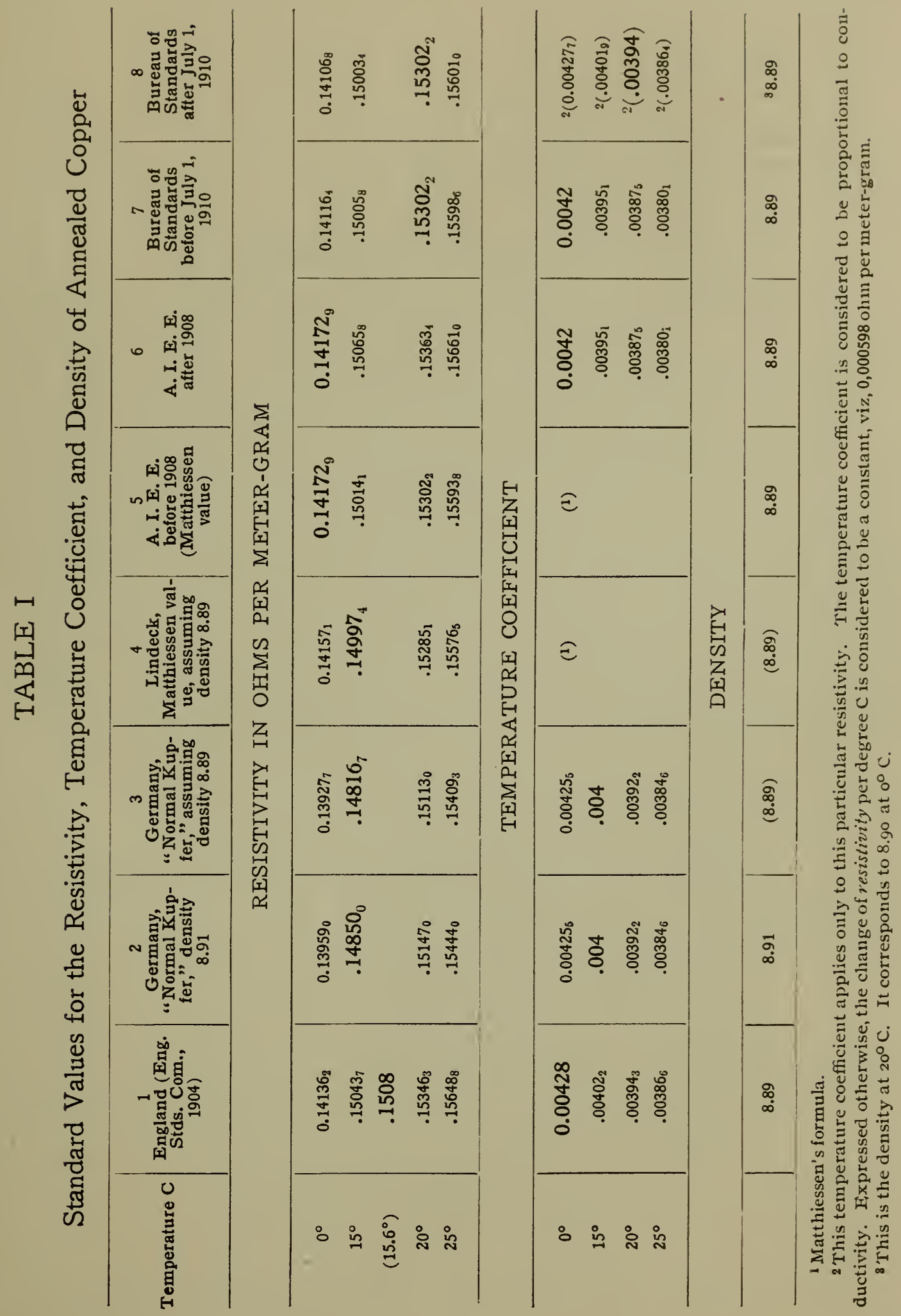


reliable as those at lower temperatures; and since the $20^{\circ}$ value was the one in practical use even on the old basis); and the temperature coefficient of 0.0042 at $0^{\circ} \mathrm{C}$ was adopted (col. 7).

Since a more accurate value for the temperature coefficient has been obtained at the Bureau of Standards, it has been applied to give the values in col. 8 , which represent the present practice of the Bureau.

\section{SCOPE OF THIS INVESTIGATION}

The foregoing table makes evident the need for data to be used in establishing more reliable standard values. The matter of obtaining such data having been submitted to the Bureau of Standards by the American Institute of Electrical Engineers, an investigation has been made of the copper furnished for electrical uses. The cooperation of a number of the important refiners and manufacturers of copper wire was secured. These companies furnished samples for measurement and information regarding their material and their practices. Incidental to the investigation of copper it was thought desirable to secure some data on aluminum, and accordingly the cooperation of the chief producer of aluminum was also secured. The companies whose material was represented in the investigation were the following:

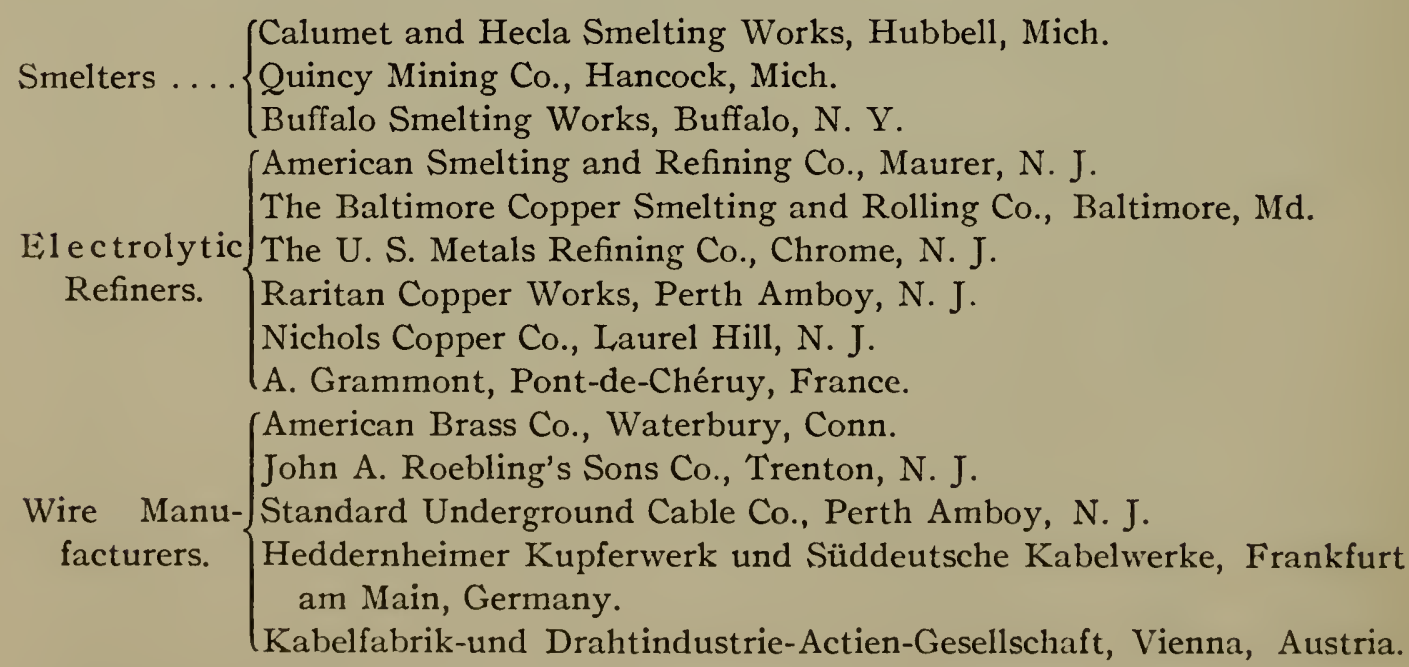

A $1 \mathrm{um}$ in u $\mathrm{m}$

Wire Manu- $\}$ Aluminum Company of America, Pittsburg, Pa.

facturer.

Eleven of these companies kindly furnished samples and information at the request of the Bureau of Standards, and the Bureau desires hereby to express its thanks and appreciation for their 
assistance. Samples of the products of the other four companies were obtained in other ways. Particular thanks is due Mr. W. H. Bassett, of the American Brass Company, who has taken great interest in the work, and who has contributed a valuable set of data on conductivity; and to Mr. Wm. Hoopes, of the Aluminum Company of America, who furnished valuable data on aluminum; and to Mr. E. A. C. Smith, of the Baltimore Copper Smelting and Rolling Company, who supplied valuable information and a quantity of specially refined cathode copper. The authors desire also to express their appreciation of the assistance of Mr. E. E. Weibel, who made some of the measurements.

A considerable number of the most important refiners and manufacturers of copper wire in this country are included in the above list; Germany, France, and Austria are each represented by one company. Since most of the world's copper is refined in this country, and the results of the measurements on the foreign samples showed no particular difference from the American samples, all the results will be given without distinguishing the foreign from the American product. The various companies were asked to furnish representative samples of their regular commercial product, both hard-drawn and annealed, and from two to twenty samples were received from each. It is not believed that the measurements made upon the few samples from each company indicate accurately the average of the product of that company, but it is considered that the mean of all the measurements indicates very well the average of the present copper of commerce. The results are given below. Results are also given for measurements on a few aluminum wires, together with the data on aluminum furnished by the Aluminum Company of America.

An effort was also made to determine what was the highest conductivity obtainable without extraordinary experimental precautions and expense, and the measurements made upon a few samples of copper of especially high conductivity are, therefore, also given. It was considered desirable also to make a complete investigation of the effect upon the conductivity of drawing to progressively smaller sizes, and to study the question of annealing, but these two matters have had to be dropped because of the pressure of other work; it is hoped that they can be taken up at a later time. 


\section{THE EXPERIMENTAL WORK}

The samples upon which measurements were made were wires Nos. 6 to $\mathrm{r} 8, \mathrm{~B}$. and S. gage, about $\mathrm{r} 20 \mathrm{~cm}$ in length. Most of the samples were No. I2. The resistivity in ohms per meter-gram and percent conductivity were computed from measurements of the length, mass, and resistance. The resistivity in ohms per meter-gram is the product of the resistance per meter and the mass per meter. The percent conductivity is computed by dividing 0.153022 by the resistance per meter-gram at $20^{\circ} \mathrm{C}$. (This figure is the value assumed by the Bureau of Standards as representing the "Matthiessen Standard" at $20^{\circ} \mathrm{C}$. It corresponds to I.72I 28 micro-ohms per centimeter cube at $20^{\circ} \mathrm{C}$, on an assumed density of 8.89.) The Thomson bridge method was used for measuring the resistances, and an accuracy of o.or percent was easily attained. The resistance of the copper sample was compared with the resistance of a copper standard in the same bath as the test sample, thus eliminating the necessity of very accurate temperature measurement. The resistances of the copper standards were carefully checked from time to time against manganin standards; in these measurements, of course, temperature as well as resistance had to be measured accurately. The accuracy of the resistivity and conductivity values obtained is believed to be within 0.03 percent, a limit determined chiefly by the uncertainty of the total length measurement (many of the wires were not entirely free from small bends) and the lack of uniformity of cross-section of the wires.

\section{THE THOMSON BRIDGE METHOD}

The Thomson bridge method was first described by Sir Wm. Thomson, ${ }^{4}$ in 1862 . Hence it is called the "Thomson bridge" or "Kelvin double bridge." A diagram of the connections is given in Fig. I. $A$ and $B$ are the low resistances to be compared. 5 and 7 , Io and I, are the "branch points" or "potential points" between which are the resistances considered. $a, n a, a^{\prime}$, and $n^{\prime} a^{\prime}$ are ratio arms of relatively high resistance. The theory of the method may be understood from Fig. 2. This figure represents

\footnotetext{
${ }^{4}$ Phil. Mag. 24, 149; r862.
} 
a simple Wheatstone bridge. 'The simple bridge can not be used for low resistances, because the connecting resistance between $A$ and $B$ introduces an error if the galvanometer is connected to any

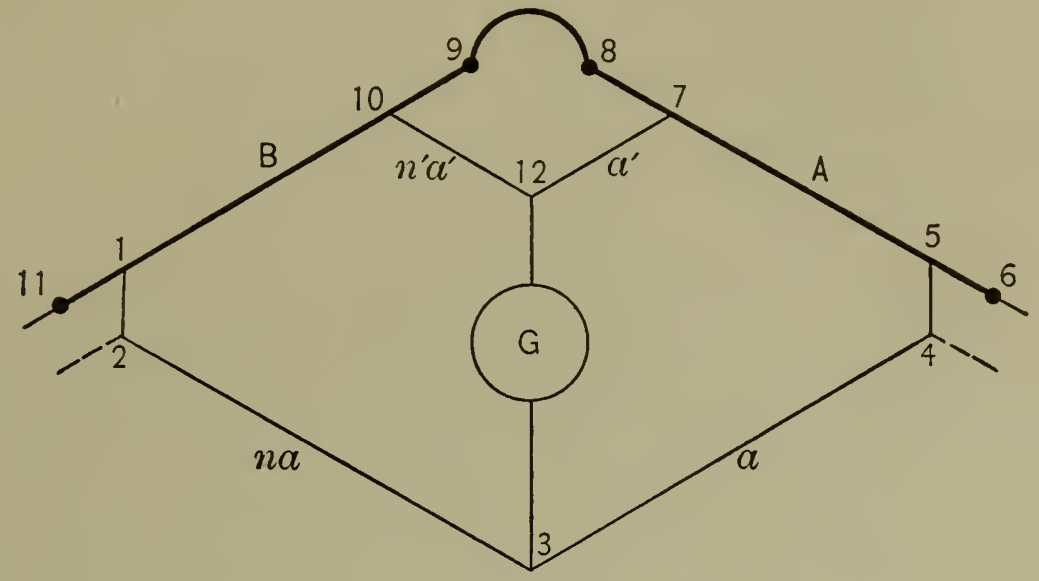

Fig. 1

of the points $7,8,9$, or Io. (The resistances $\overline{78}$ and $\overline{9}$ io are the resistances of the adjacent "current terminals" of $A$ and $B$. The resistance between 8 and 9 is the "link" connecting $A$ and $B$.)

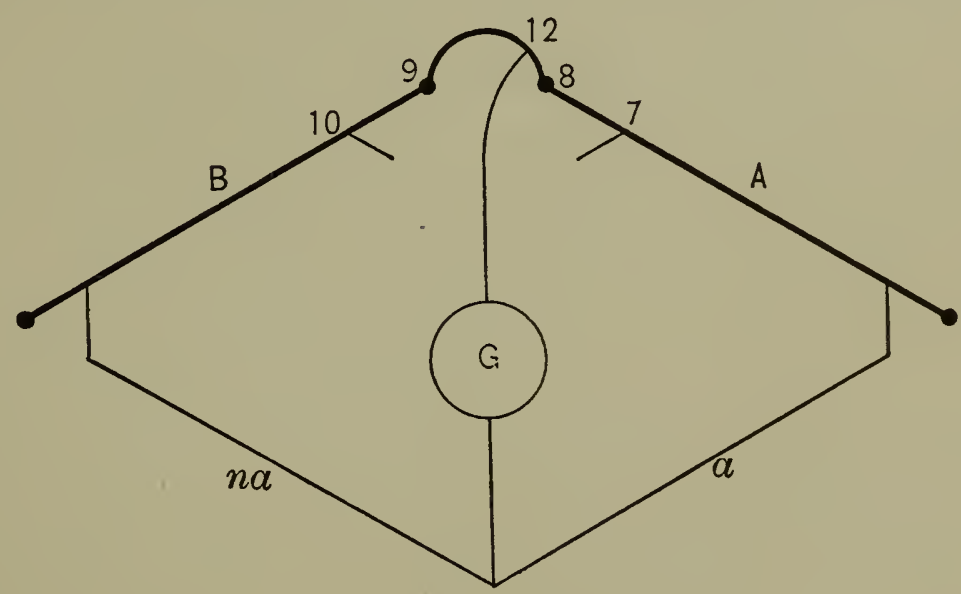

Fig. 2

However, if it were possible to bring the galvanometer lead in at some point $\mathrm{I} 2$ such that

$$
\overline{\frac{\mathrm{IO} \mathrm{I} 2}{\mathrm{I} 27}}=\frac{B}{A}
$$

since, for zero deflection of the galvanometer,

$$
\frac{B+\overline{\mathrm{IO} \mathrm{I2}}}{A+\overline{\mathrm{I} 27}}=\frac{n a}{a}
$$


we have, for a bridge balance,

$$
\frac{B}{A}=n
$$

The equivalent of this is accomplished in the Thomson bridge by shunting $\overline{\text { IO } 7}$ with a relatively high resistance, connecting the galvanometer to a point, I2, Fig. I, and adjusting $n^{\prime} a^{\prime}$ or $a^{\prime}$ so that

$$
\frac{n^{\prime} a^{\prime}}{a^{\prime}}=\frac{B}{A}
$$

The best method of accomplishing this adjustment (first published by J. H. Reeves ${ }^{5}$ ) is to remove the link, $\overline{89}$, thus reducing the bridge to a simple Wheatstone bridge, and vary $a^{\prime}$ or $n^{\prime} a^{\prime}$ for a galvanometer balance. Then $n=n^{\prime}$. The link is then replaced, and the main ratio, $n a: a$, adjusted until a galvanometer balance is attained. The "link-out" balance is, of course, disturbed by this adjustment, unless $\left(n^{\prime} a^{\prime}: a^{\prime}\right)$ is varied simultaneously with $(n a: a)$. It is preferable to have the "auxiliary ratio," $n^{\prime} a^{\prime}: a^{\prime}$, similar to the main ratio, and to vary them simultaneously for the "link-in" balance; thus the "link-out" adjustment is not disturbed. A double set of ratio coils frequently used is the O. Wolff type, and it was used in the work of this paper. If, however, the main and auxiliary ratios can not be varied simultaneously, the "link-in" balance may be made by varying the main ratio, then the link is taken out and the balance restored by varying the auxiliary ratio, and then the link is replaced and the main ratio again varied, and so on by successive approximations until both balances are made.

The variation of $a^{\prime}$ or $n^{\prime} a^{\prime}$ for the "link-out" balance may be accomplished by means of a variable resistance in series with $a^{\prime}$ or $n^{\prime} a^{\prime}$, at 7 or ro. A very satisfactory form for this variable resistance is a small glass tube of mercury, the resistance between the ends of which can be varied by changing the depth to which an amalgamated copper wire is immersed in it. If the range of the mercury resistance is insufficient, a manganin wire, with sliding clamp contact, may be put in series with it. Another method for obtaining the "link-out" balance is to have a slide-wire between $a^{\prime}$ and $n^{\prime} a^{\prime}$, along which moves the galvanometer contact. 
The connecting resistances between the branch-point, I, and the end of $n a, 2$, and between 5 and 4 , are usually not negligible. One method of procedure is to shift the battery leads from their normal points of connection, 6 and II, to 4 and 2, with the link out, and measure the change of balance of the bridge by varying one of the four ratio arms. The connecting resistances are then calculated from the change of balance. The variation of one of the ratio arms to measure the change of balance may be accomplished by shunting or by varying a series resistance. In the work of this paper a small series resistance was placed in one arm, say $a^{\prime}$, the total resistance of the arm having the fixed value, 100 ohms. The small series resistance could be put in circuit or out by means of a plug, and was normally out of circuit. When the link-out balance had been made, this series resistance was put in circuit and the galvanometer deflection noted. The deflection corresponding to a given change of balance of the bridge being thus known, the change of balance caused by shifting the battery leads was obtained by observing the deflection caused by the shift, and thence the correction to the ratio, na: $a$, easily calculated. The connecting resistances between $\mathrm{I}$ and 2 and between 4 and 5 are often neglected by users of the Thomson bridge. Since they are frequently appreciable (often including the resistance of a knife-edge contact), and also since the method of this paragraph permits the correction to be readily determined, they should not be neglected.

A different method of using the Thomson bridge is to have fixed ratio arms and a variable low resistance standard. The method of measurement described above, or an equivalent method, should, however, be followed throughout, except that the link-in balance is made by varying the standard (which would be in the arm $A$ or $B$ ) instead of by varying the ratio arms.

\section{THE APPARATUS}

The apparatus used in the resistance measurements consisted of an Otto Wolff "double bridge" and a special apparatus for mounting the wires under measurement. This special apparatus was designed by the authors, and it was constructed and the details of design were worked out by the Leeds and Northrup 
Company. It consisted essentially of a rectangular oil bath provided with means for temperature control, and a base with electrical connections to the wire under measurement. A photograph of the apparatus is given herewith. The base upon which wires were mounted was a piece of marble, I $2 \mathrm{I} \mathrm{cm}$ long and $22 \mathrm{~cm}$ wide. The bath was provided with pipes for the flow of cooling water, and with electric heating coils and lamps, all placed beneath the marble base. An efficient thermoregulator was provided, similar in general to those described in this Bulletin 4, p. 34; 1907. The "bulb" of this thermoregulator consisted of $500 \mathrm{~cm}$ of copper tubing passing around the bath in two turns, as may be seen from the photograph. A motor-driven propeller forced the oil through a vertical tube at one end of the bath, and thus produced a circulation of the oil in one direction over the marble, and in the opposite direction under the marble. The wire sample was held by heavy screw clamps at the ends of the base. The test current was passed through the wire by means of these clamps. The potential connections were steel knife-edges which were mounted rigidly I meter apart on the marble base. Between the knifeedges a row of small hard rubber blocks served to support the wire sample. Spring pressure devices, pressing from above, kept the wire in contact with the fixed knife-edges. A movable knifeedge was also provided, traveling along a steel scale graduated for I $03 \mathrm{~cm}$. Its contact pressure is adjusted by a lever and weights. This knife-edge makes it possible to measure the resistance of a sample of any length. Its position is capable of fine adjustment by a cone and socket device, and is readable by means of a vernier to o. I $\mathrm{mm}$.

On account of the advantages of measuring samples against a standard of the same material in the same bath, frames for auxiliary copper standards were provided. These standards were wires about a meter long, with soldered potential terminals. Such a standard was placed in a frame, with its ends connected into small clamps, and its potential leads connected to binding posts. The two clamps and the two binding posts terminated in amalgamated copper rods. Mercury cups in the marble base were so placed as to receive these amalgamated terminals. When the frame was in place, the auxiliary copper standard lay parallel to 


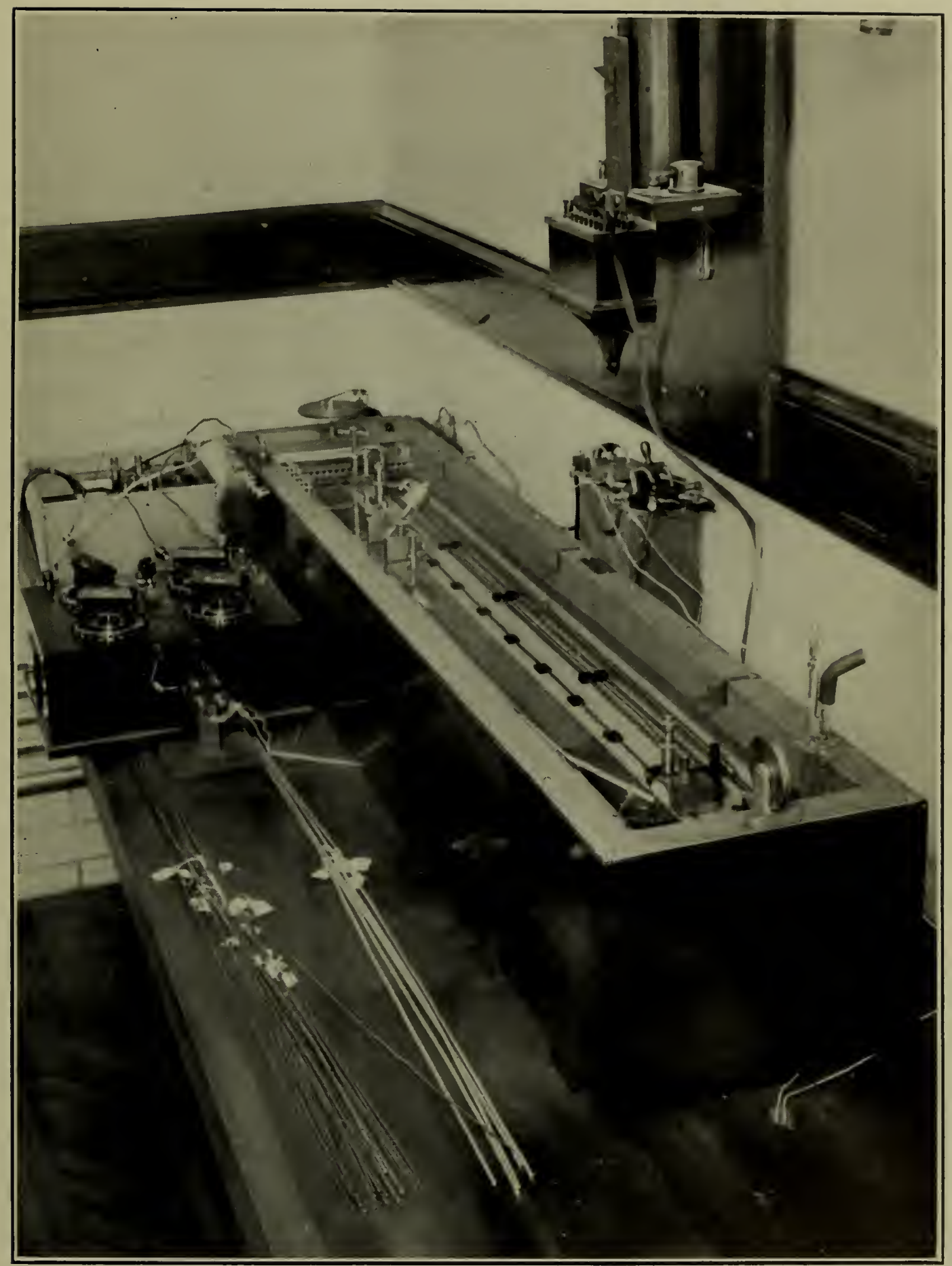

Fig. 3. Conductivity Apparatus. 
the wire sample under measurement. The wire sample could be put into connection either with the auxiliary copper standard or with a manganin standard in a separate bath, by means of a movable amalgamated copper link. All connections were carried under the marble to binding posts on one side of the apparatus.

The apparatus was provided also with means for applying a known tension to the wire under measurement. This consisted of a pair of pulleys at one end of the bath, with a pan and weights for attaching to a cord clamped to one end of the wire sample. The effect of tension has to be considered when measuring the resistances of small wires. Experiments showed that for an increase of tension of I kilogram per $\mathrm{mm}^{2}$ cross section, the resistance increased 0.025 percent, which corresponds to an increase of specific resistance of o.or I percent. For example, if a No. I 8 wire is under a tension of I kilogram, its resistance is 0.030 percent greater than if no tension is applied.

\section{RESULTS OBTAINED}

\section{RESISTIVITY OF COMMERCIAL COPPER}

The resistivity and percent conductivity of 89 copper wires are given in Table 2. The results are separated into groups, each group representing one company's samples. The order in which the groups are placed has no relation to the order in which the names of the companies are given on page ro6. It is not desired that the few samples from each company be considered an adequate basis of judging the output of the company, although the final mean is believed to be a good indication of the average output of all.

In general, the conductivity of the annealed wires did not differ with the size of the wire, but in the case of the hard-drawn wires there were well-defined differences. (N. B.: The No. Io wires are considered together with the No. I 2 throughout, there being no appreciable difference.) In each group, accordingly, the mean of all the annealed wires is taken, and for the hard-drawn wires the mean of each size of wire in the group is taken.

The mean of the 14 group means for the annealed wires is:

Resistivity in ohms per meter-gram at $20^{\circ} \mathrm{C}=0.15292$ Percent conductivity $=\mathrm{I} 00.07 \%$ 
The average deviation from these means was $0.26 \%$, and the maximum deviation of any group was $0.8 \mathrm{r} \%$.

Values for annealed and hard-drawn wires being placed on the same line indicates that they are from the same lot of material, and should therefore correspond. In calculating "Annealed minus Hard-Drawn, Mean Percent Conductivity," col. Io, the mean of the particular size of wire in the group is taken.

For the No. 6 wires, the mean difference, annealed minus harddrawn, is $2.30 \%$.

For the No. I 2 wires, the mean difference was $2.68 \%$, with a mean deviation of $0.14 \%$. Inasmuch as one company's samples were all hard-drawn and two companies' all annealed, these differences for corresponding groups do not include all the No. I 2 wires. The mean difference might, therefore, also be computed in another way; taking the difference between the mean of all the annealed wires and the mean of all the No. I 2 hard-drawn wires and subtracting, the result is $2.57 \%$. This value agrees with the above, within the mean deviation above. The value may, therefore, be stated to be $2.7 \%$

For the No. I 8 wires the mean difference was $3.09 \%$.

\section{COPPER OF ESPECIALLY HIGH CONDUCTIVITY}

Samples of electrolytic copper wire, drawn directly from cathode plates without intermediate melting, were prepared for this investigation by two of the refiners, the U. S. Metals Refining Company and the Baltimore Copper Smelting and Rolling Company. The values of resistivity and conductivity for two samples from each refiner are given herewith. The first three samples were annealed, and the fourth was a hard-drawn No. 22 wire.

\begin{tabular}{c|c}
\hline Ohms per meter-gram at $20^{\circ} \mathrm{C}$ & Percent conductivity \\
\hline 0.15101 & $101.33 \%$ \\
0.15098 & $101.35 \%$ \\
0.15076 & $101.50 \%$ \\
0.15386 & $99.46 \%$ \\
\hline
\end{tabular}

It was thought that still higher conductivity could be obtained by melting the cathode plates in vacuo, and drawing wires from the rods resulting. This was carried out, with the assistance of 
TABLE II

Values Found for Resistivity and Conductivity of Commercial Copper Wires

\begin{tabular}{|c|c|c|c|c|c|c|c|c|c|}
\hline \multirow{2}{*}{$\begin{array}{l}\text { Sire of Wire! } \\
\text { B. \& S. }\end{array}$} & \multirow{2}{*}{$\begin{array}{c}\text { Ohms per } \\
\text { metor-ghem } \\
3120^{\circ} \mathrm{C}\end{array}$} & \multicolumn{2}{|c|}{ Annealed } & \multicolumn{5}{|c|}{ Esrd-drawn } & \multirow{2}{*}{$\begin{array}{l}\text { Anacaied } \\
\text { minus bard- } \\
\text { drawn. mean } \\
\text { Percent } \\
\text { Conductivly }\end{array}$} \\
\hline & & $\begin{array}{l}\text { Mean ohms } \\
\text { per meter- } \\
\text { gram at } 20^{\circ} \mathrm{C}\end{array}$ & $\begin{array}{c}\text { Percent } \\
\text { Conducttvity }\end{array}$ & $\begin{array}{l}\text { Mean Percent } \\
\text { Couductsvity }\end{array}$ & $\begin{array}{l}\text { Ohms per } \\
\text { metei-rram } \\
3120^{\circ} \mathrm{C}\end{array}$ & $\begin{array}{l}\text { Mean ohuis } \\
\text { Der meter- } \\
\text { gram at } 20^{\circ} \mathrm{C}\end{array}$ & $\begin{array}{c}\text { Percent } \\
\text { Conductivity }\end{array}$ & $\begin{array}{l}\text { Mean Perceat } \\
\text { Conductivity }\end{array}$ & \\
\hline 6 & 0.15268 & & $100.22 \%$ & & 0.15635 & & $97.87 ;$ & & \\
\hline 6 & .15280 & & 100.15 & & . J5658 & 0.15648 & $97.72^{\circ}$ & $97.78 \%$ & $2.40 \%$ \\
\hline 6 & .15274 & & 100.18 & & .15652 & & 97.75 & & \\
\hline 12 & .15258 & & 100.29 & & .15704 & & 97.44 & & \\
\hline 12 & .15266 & 0.15267 & 100.24 & $100.23 \%$ & .15702 & .15698 & 97.46 & $97.48 \%$ & 2.84 \\
\hline 12 & .15235 & & 100.44 & & .15689 & & 97.54 & & \\
\hline 18 & .15332 & & 99.80 & & .15801 & & 96.84 & & \\
\hline 18 & .15226 & & 100.51 & & .15725 & .15759 & 97.31 & $97.10 \%$ & $3.09 C_{c}$ \\
\hline 18 & .15263 & & 100.25 & & .15751 & & 97.15 & & \\
\hline 12 & .15306 & & 99.97 & & .15671 & & 97.64 & & \\
\hline 12 & .15285 & .15294 & 100.11 & $100.06 \%$ & .15700 & .15700 & 97.47 & $97.47 \%$ & $2.59 \%$ \\
\hline 12 & .15290 & & 100.09 & & .15729 & & 97.29 & & \\
\hline 12 & .15309 & & 99.96 & & & & & & \\
\hline 12 & .15289 & & 100.09 & & & & & & \\
\hline 12 & .15263 & .15273 & 100.26 & $100.20 \%$ & .15640 & & 97.84 & & \\
\hline 12 & .15238 & & 100.43 & & .15602 & .15639 & 98.08 & $97.84 \%$ & $2.47 \%$ \\
\hline 12 & .15265 & & 100.24 & & .15676 & & 97.61 & & \\
\hline 12 & & & & & .15585 & & 98.18 & & \\
\hline 12 & & & & & .15575 & & 98.25 & & \\
\hline 12 & & & & & .15604 & .15606 & 98.06 & $98.05 \%$ & \\
\hline 12 & & & & & .15609 & & 98.03 & & \\
\hline 12 & & & & & .15656 & & 97.74 & & \\
\hline 6 & .15299 & & 100.02 & & & & & & \\
\hline $\begin{array}{l}12 \\
12\end{array}$ & $\begin{array}{l}.15344 \\
.15278\end{array}$ & .15330 & $\begin{array}{r}99.73 \\
100.16\end{array}$ & $99.82 \%_{n}$ & 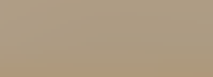 & & & & \\
\hline $\begin{array}{l}12 \\
18\end{array}$ & .15401 & & $\begin{array}{r}100.16 \\
99.36\end{array}$ & & & & & & \\
\hline 12 & .15359 & 15333 & 09.63 & 0080 & .15848 & & 96.56 & & \\
\hline 12 & .15307 & (1) & 99.97 & $99.007 n$ & .15783 & .15810 & 96.96 & 90.70 & $3.04 \%$ \\
\hline 10 & .15320 & .15320 & 99.89 & 99.89 年 & .15747 & .15747 & 97.16 & $97.16 \%$ & $2.73 \%$ \\
\hline 12 & .15341 & & 99.75 & & .15764 & & 97.07 & & \\
\hline 12 & .15260 & .15306 & 100.28 & $99.97 \%$ & .15713 & .15743 & 97.39 & $97.20 \%$ & $2.57 \%$ \\
\hline 12 & .15318 & & 99.89 & & .15752 & & 97.14 & & \\
\hline 12 & .15274 & & 100.19 & & .15663 & & 97.70 & & \\
\hline 12 & .15230 & 15235 & 100.47 & $100.44 \sigma^{\prime}$ & .15602 & 15617 & 98.08 & 97.99 & $245 \%$ \\
\hline 12 & .15243 & & 100.39 & 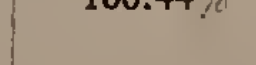 & .15621 & .10014 & 97.96 & 91.3976 & $2.45 \%$ \\
\hline 12 & .15195 & & 100.70 & & .15581 & & 98.21 & & \\
\hline 6 & .15116 & & 101.23 & & .15450 & & 99.04 & & \\
\hline 6 & .15120 & 15169 & 101.20 & $100.88 \%$ & .15457 & .15454 & 99.00 & $99.02 \frac{1}{k}$ & $2.20 \%$ \\
\hline 12 & .15221 & & 100.54 & & .15639 & .15636 & 97.84 & $97.86 / i$ & $2.68 \%$ \\
\hline 12 & .15218 & & 100.56 & & .15633 & & 97.88 & & \\
\hline 6 & .15269 & 15278 & 100.21 & $10018 \%$ & .15629 & .15629 & 97.90 & $97.90 \%$ & $2.31 \%$ \\
\hline 12 & .15280 & .10274 & 100.14 & $100.10 \%$ & .15733 & .15733 & 97.25 & $97.25 \pi$ & 2.89 \\
\hline 12 & .15434 & 15415 & 99.14 & 0026 & & & & & \\
\hline 12 & .15396 & .10410 & 99.39 & $30.40, \mathrm{n}$ & & & & & \\
\hline 12 & .15263 & & 100.26 & & .15687 & & 97.54 & & \\
\hline 12 & .15343 & .15303 & 99.74 & $100.00 \%$ & .15782 & .15715 & 96.95 & $97.37 \%$ & $2.63 \%$ \\
\hline 12 & .15303 & & 99.99 & & .15765 & & 97.62 & & \\
\hline 10 & .15533 & & 98.51 & & .15939 & & 95.99 & & \\
\hline 10 & .15170 & .15280 & 100.87 & $100.16=$ & .15598 & .15688 & 98.11 & $97.53 \%$ & $2.63 \%$ \\
\hline 10 & .15219 & & 100.54 & & .15563 & & 28.32 & & \\
\hline 12 & .15197 & & 100.70 & & .15653 & & 97.75 & & \\
\hline
\end{tabular}


the Research Laboratory of the General Electric Company, and Mr. W. H. Bassett, of the American Brass Company. The results on a sample melted in a hole of $2 \mathrm{~cm}$ diameter in a special crucible of Acheson graphite are given herewith. The first is for annealed wire, and the second for hard-drawn No. I 8 wire:

\begin{tabular}{c|c}
\hline Ohms per meter-gram at $20^{\circ} \mathrm{C}$ & Percent conductivity \\
\hline 0.15046 & $101.70 \%$ \\
0.15483 & $98.83 \%$ \\
\hline
\end{tabular}

Other samples melted in alumina and graphite crucibles had conductivity less than before the vacuum treatment. It is believed that better results in this direction could be obtained, but time to attack the problem was not available.

Wires were submitted by the Quincy Mining Company, drawn from a mass of native lake copper of unusually high conductivity. The copper had never been melted down. The values found are given herewith. The first is a hard-drawn No. 12 wire, the second annealed.

\begin{tabular}{c|c}
\hline Ohms per meter-gram at $20^{\circ} \mathrm{C}$ & Percent conductivity \\
\hline 0.15431 & $99.17 \%$ \\
0.15045 & $101.71 \%$ \\
\hline
\end{tabular}

\section{DATA ON HARD-DRAWN ALUMINUM}

Seven samples of wire, together with the following table of information, were furnished by the Aluminum Company of America.

TABLE III

\begin{tabular}{c|c|c|c|c}
\hline & & \multicolumn{3}{|c}{ Analysis } \\
\cline { 2 - 4 } Sample No. & Conductivity & $\mathrm{Al}$ & $\mathrm{Si}$ & $\mathrm{Fe}$ \\
\hline 1 & 62.1 & 99.58 & .27 & .15 \\
2 & 61.6 & 99.60 & .26 & .14 \\
3 & 61.6 & 99.58 & .27 & .15 \\
4 & 61.6 & 99.59 & .27 & .14 \\
5 & 61.8 & 99.59 & .27 & .14 \\
6 & 62.0 & 99.55 & .31 & .14 \\
7 & & 99.52 & .34 & .14 \\
\hline
\end{tabular}


The results of measurements at the Bureau of Standards are given in the following table:

TABLE IV

\begin{tabular}{c|c|c|c|c|c|c}
\hline Sample No. & $\begin{array}{c}\text { Size of } \\
\text { Wire } \\
\text { B. and S. }\end{array}$ & Density & $\begin{array}{c}\text { Ohms per } \\
\text { meter-gram } \\
\text { at } 20.00^{\circ} \mathbf{C}\end{array}$ & $\begin{array}{c}\text { Micro-ohms } \\
\text { per cm cube } \\
\text { at } 20.00^{\circ} \mathbf{C}\end{array}$ & $\begin{array}{c}\text { Percent con- } \\
\text { ductivity on } \\
\text { meter-gram } \\
\text { basis }\end{array}$ & $\begin{array}{c}\text { Percent con- } \\
\text { ductivity on } \\
\text { cm cube } \\
\text { basis }\end{array}$ \\
\hline 1 & 6 & 2.6983 & 0.07575 & 2.8074 & $202.01 \%$ & $61.31 \%$ \\
2 & 6 & 2.6996 & 0.07604 & 2.8168 & $201.23 \%$ & $61.11 \%$ \\
3 & 6 & 2.6994 & 0.07579 & 2.8076 & $201.91 \%$ & $61.31 \%$ \\
4 & 6 & 2.6992 & 0.07602 & 2.8165 & $201.30 \%$ & $61.11 \%$ \\
5 & 6 & 2.6992 & 0.07605 & 2.8175 & $201.21 \%$ & $61.09 \%$ \\
6 & 12 & 2.6991 & 0.07535 & 2.7917 & $203.08 \%$ & $61.66 \%$ \\
7 & 16 & 2.6984 & 0.07514 & 2.7845 & $203.66 \%$ & $61.82 \%$ \\
Mean & 16 & 2.6990 & 0.07573 & 2.8060 & $202.06 \%$ & $61.34 \%$ \\
\hline
\end{tabular}

The two values assumed as standard in computing the two percent conductivities are the values assumed in the case of copper, viz, O.I53022 ohm per meter-gram at $20^{\circ} \mathrm{C}$, and I.72I 28 microohms per $\mathrm{cm}$ cube at $20^{\circ} \mathrm{C}$.

The company also furnished a figure representing the mean conductivity of its output of all sizes of wire for the past five years. The figure was obtained by averaging the records for one out of every 15 conductivity tests during the above period. As the figure is the result of many thousands of separate determinations it is of great value. This figure was given as " 61.38 on the Matthiessen standard scale." This was translated into resistivity values by applying as a correction the difference between the mean of the percent conductivity values on the first six samples above, as determined by the company, and as determined at the Bureau of Standards, and using the mean density found above. The correction takes into account both errors of measurement and a difference in the standard values assumed.

The results then were:

Percent conductivity on cm cube basis $=60.86 \%$

Resistivity in micro-ohms per centimeter cube at $20^{\circ} \mathrm{C}=2.8283$

Resistivity in ohms per meter-gram at $20^{\circ} \mathrm{C}$

$=0.07633$

Percent conductivity on meter-gram basis

$=200.46 \%$ 


\section{DISCUSSION OF RESULTS}

\section{ANNEALED COPPER WIRES}

(A) SUMMARY OF ABOVE DATA

It was found that annealed copper wires did not differ in conductivity with the size of wire. For the annealed samples from I 4 important producers the mean results were:

Resistivity in ohms per meter-gram at $20^{\circ} \mathrm{C}=0.15292$

Percent conductivity $=100.07 \%$

The average deviation from these means was 0.26 percent, and the maximum deviation of any group was $0.8 \mathrm{I}$ percent. The general agreement of the results indicates that the refiners are producing copper very satisfactory in its uniformity of quality.

(B) SUMMARY OF DATA FROM AMERICAN BRASS COMPANY

We present here also the results of the data collected by the American Brass Company, which were furnished by Mr. W. H. Bassett, and which are given with his permission. Measurements were made upon annealed No. I 2 samples, at least one sample from each carload of wire bars. The wire bars represented a number of the important refiners of copper. Practically all the material had been electrolytically refined. For samples from more than 2000 carloads, or more than 100000 ooo pounds of wire bar copper:

Mean resistivity in ohms per meter-gram at $20^{\circ} \mathrm{C}=0.15263$

Mean percent conductivity

$$
=100.25 \%
$$

This result is regarded as reliable, as the work of this laboratory is known to be done with care, and as its standards for conductivity measurements are in agreement with those of the Bureau of Standards. This result is much more representative, in pounds of copper, than the result just given above. The fact that the value for conductivity is higher is corroborative of the former result, because this company (like others who make conductivity tests) accepts only copper of the higher conductivity.

It is to be observed that both the mean values as found in this investigation, and as found by Mr. Bassett, for the resistivity and percent conductivity differ from the standard values (o. 53022 and 100 percent) by less than 0.26 percent, which is the 
above average deviation from the mean. It is interesting that the standard values, derived from the experiments of fifty years ago on copper supposed to be chemically pure, are so close to the average of commercial copper to-day. It at once suggests itself that the present standard of resistivity is a good one to retain for commercial copper.

\section{HARD-DRAWN COPPER WIRES}

The results on the hard-drawn wires may best be summarized by considering the difference in conductivity between annealed and hard-drawn samples. It was found that this difference in conductivity varies with the size of the wire. Most of the wires used were No. I 2 B. and S., and for that size the conductivity of annealed wires was found to be greater than the conductivity of harddrawn wires by 2.7 per cent.

Only a few No. 6 and No. I 8 wires were experimented upon, and the mean results are stated above. The values are not considered as having much weight, being based on such limited experimental evidence, but they show, as was to be expected, that the difference between the conductivity of annealed and hard-drawn wires increases as the diameter of the wire decreases. This general conclusion is, however, complicated in any particular case by the particular practice of the wire drawer, in regard to the number of drawings between annealings, amount of reduction to each drawing, etc.

\section{THE HIGHEST CONDUCTIVITY FOUND}

The lowest resistivity and highest conductivity found, for a hard-drawn wire, were:

Resistivity in ohms per meter-gram at $20^{\circ} \mathrm{C}=0.15386$

Percent conductivity $\quad=99.46 \%$

and for an annealed wire, were:

Resistivity in ohms per meter-gram at $20^{\circ} \mathrm{C}=0.15045$

Percent conductivity $\quad=101.71 \%$

The former wire was drawn from a cathode plate without melting. The latter wire was drawn directly from a mass of native lake copper which had never been melted down. It was thought that a still higher conductivity could be obtained if a wire could be 
prepared from cathode copper which had been melted in vacuo. This was tried and no material increase of conductivity was obtained. This may, however, have been due to contamination from the crucibles or to the poor mechanical condition of the samples resulting from the melting. It is believed that further investigation along this line, with care in the methods of cooling, might be rewarded with a higher conductivity than any yet obtained.

\section{ALUMINUM}

Data on the conductivity of hard-drawn aluminum is given above. For 7 samples of commercial aluminum, supposed to be fairly representative of the present output of the Aluminum Company of America, the mean results were:

Resistivity in ohms per meter-gram at $20^{\circ} \mathrm{C}$ $=0.07573$

Resistivity in micro-ohms per centimeter cube at $20^{\circ} \mathrm{C}=2.8060$

Density

$$
=2.699
$$

The chemical analysis of these wires is also given above. The mean resistivity of the company's output of all sizes of wire for the past five years was furnished by the company. The value was given by the company in terms of the resistance per centimeter cube, and has been reduced to the meter-gram basis by the use of the density just stated. The values are:

Resistivity in ohms per meter-gram at $20^{\circ} \mathrm{C}=0.07633$

Resistivity in micro-ohms per $\mathrm{cm}$ cube at $20^{\circ} \mathrm{C}=2.8283$

Percent conductivity on cm cube basis

$=60.86 \%$

Percent conductivity on meter-gram basis$$
=200.46 \%
$$

This result is considered to be a very good average value for commercial hard-drawn aluminum. It is, of course, entitled to much greater consideration than the above results on 7 samples.

Aluminum wire is always furnished hard-drawn, hence no data is given on annealed samples.

\section{TEMPERATURE COEFFICIENT OF COPPER}

The work on the temperature coefficient, reported in the paper on "The Temperature Coefficient of Resistance of Copper," s was 
done upon samples included in this investigation. The temperature coefficient was found to be linear between $10^{\circ} \mathrm{C}$ and $100^{\circ}$ $\mathrm{C}$ to an accuracy within $0.2 \%$, and to be proportional to the conductivity, the mean deviation from this relation being only $0.2 \%$ for the 37 samples measured. The temperature coefficient at $20^{\circ} \mathrm{C}$ of a sample of copper is accordingly given by multiplying the number expressing the percent conductivity decimally by

$$
0.00394
$$

In the paper mentioned is given a table showing the temperature coefficients for various conductivities over the range of commercial copper, calculated according to the above simple rule. The relation between conductivity and temperature coefficient may be expressed otherwise, thus: the change of resistivity per degree $\mathrm{C}$ is a constant for copper, independent of the temperature of reference and independent of the sample of copper. This constant is:

$$
\begin{aligned}
& 0.000598 \text { ohm per meter-gram, } \\
& \text { or, o.0068 I micro-ohm per centimeter cube. }
\end{aligned}
$$

Cases sometimes arise in practice where a temperature coefficient of resistance must be assumed. It may be concluded from these results that the best value to assume for the temperature coefficient of good commercial annealed copper wire is that corresponding to $100 \%$ conductivity, viz:

$$
\begin{gathered}
\alpha_{0}=0.00428, \quad \alpha_{15}=0.00402, \quad \alpha_{20}=0.00394, \quad \alpha_{25}=0.00386 \\
\left(\alpha_{20}=\frac{R_{t}-R_{20}}{R_{20}(t-20)} \text {, etc. }\right) \text {. This value would usually apply to instru- }
\end{gathered}
$$
ments and machines, since they are generally wound with annealed wire. Similarly, the temperature coefficient of good commercial hard-drawn copper wire may be taken as that corresponding to a conductivity $2.7 \%$ less, viz:

$$
\alpha_{0}=0.004 \text { I } 5, \quad \alpha_{15}=0.0039 \mathrm{I}, \quad \alpha_{20}=0.00383, \quad \alpha_{25}=0.00376 .
$$




\section{CONCLUSIONS}

\section{BEST VALUE FOR THE RESISTIVITY OF ANNEALED COPPER}

The mean value found for the $20^{\circ} \mathrm{C}$ resistivity of commercial annealed copper is very close to the standard value previously assumed by the Bureau of Standards and by the American Institute of Electrical Engineers before I908. We are accordingly led to the conclusion that the best value to be assumed for the resistivity of annealed copper, in the preparation of wire tables and in the expression of percent conductivity, etc., is said standard value, viz:

\section{$0.153022 \mathrm{ohm}$ per meter-gram at $20^{\circ} \mathrm{C}$}

Thus, three of the standard $20^{\circ} \mathrm{C}$ values in Table I, page I05, are in agreement. The standard values at other temperatures, however, are not in agreement because of differences in the temperature coefficient assumed. Applying the temperature coefficient which is discussed above, page $\mathrm{i} 2 \mathrm{O}$, and which is equivalent to a change of resistivity per degree $\mathrm{C}$

$$
=0.000598 \mathrm{ohm} \text { per meter-gram, }
$$

we obtain the following values of the standard resistivity at various temperatures:

\begin{tabular}{c|c}
\hline Temperature Centigrade & \multicolumn{1}{|c}{ Resistivity in ohms per meter-gram } \\
\hline $0^{\circ}$ & 0.1411 \\
$15^{\circ}$ & 0.1500 \\
$20^{\circ}$ & 0.153022 \\
$25^{\circ}$ & 0.1560 \\
\hline
\end{tabular}

It will be noticed that the value 0.1500 at $15^{\circ} \mathrm{C}$ is a round number easily remembered, and happens to agree with the $15^{\circ} \mathrm{C}$ value of the Matthiessen Standard as computed by Lindeck (col. 4, Table I). It is proposed that the resistivity represented by the foregoing values be called the "Annealed Copper Standard." (The term "Matthiessen Standard" has been applied to too many different values to be considered.) 


\section{DENSITY OF COPPER}

When it is desired to calculate the resistance of wires from dimensions, it is necessary that a density be given, as well as the meter-gram resistivity. It is proposed that the standard density for copper, at $20^{\circ} \mathrm{C}$, be taken as 8.89 . This is the value which has been used by the A. I. E. E., and most other authorities. Measurements made on a number of the samples in this investigation indicated this value as a mean. This density, of 8.89 , at $20^{\circ} \mathrm{C}$, corresponds to a density of 8.90 at $0^{\circ} \mathrm{C}$. Applying the above values of density and of meter-gram resistivity, the resistivity of the "Annealed Copper Standard" is found to be equivalent to a specific resistance of $1.72 \mathrm{I} 28$ micro-ohms per centimeter cube at $20^{\circ} \mathrm{C}$, or a specific conductivity of 5.8096 (IO) $)^{-4} \mathrm{cgs}$ units at $20^{\circ} \mathrm{C}$.

\section{TEMPERATURE COEFFICIENT OF ANNEALED AND OF HARD-DRAWN COPPER}

According to the above discussion of the temperature coefficient, page $\mathrm{I} 2 \mathrm{O}$, it is proposed that, in cases where assumption is unavoidable, the temperature coefficient of good commercial annealed copper wire be assumed as:

$$
\alpha_{0}=0.00428, \quad \alpha_{15}=0.00402, \alpha_{20}=0.00394, \alpha_{25}=0.00386,
$$

and that the temperature coefficient of good commercial harddrawn copper wire be assumed as:

$$
\alpha_{0}=0.004 \mathrm{I}_{5}, \quad \alpha_{15}=0.0039 \mathrm{I}, \quad \alpha_{20}=0.00383, \quad \alpha_{25}=0.00376 \text {. }
$$

\section{PERCENT CONDUCTIVITY}

Percent conductivity of a sample of copper may be calculated by dividing the resistivity of the Annealed Copper Standard at $20^{\circ} \mathrm{C}$ by the resistivity of the sample at $20^{\circ} \mathrm{C}$. Inasmuch as the temperature coefficient of copper varies with the conductivity, it is to be noted that a different value will be found if the resistivity at some other temperature is used. This difference is of practical moment in some cases. For example, suppose the resistivity of a sample of copper is 0.1594 at $20^{\circ} \mathrm{C}$; dividing 0.1530 by this, the percent conductivity is $96.0 \%$. Now the corresponding $0^{\circ} \mathrm{C}$ resistivity of the sample is 0.1474 ; dividing $0.14 \mathrm{I}$. I by this, the percent conductivity 
is calculated to be $95.7 \%$. In order that such differences shall not arise, it is suggested that the $20^{\circ} \mathrm{C}$ value of resistivity always be used in computing the percent conductivity of copper. When the resistivity of the sample is known at some other temperature, $t$, it is very simply reduced to $20^{\circ} \mathrm{C}$ by adding the quantity, $(2 \mathrm{O}-t)$ multiplied by 0.000598 ohm per meter-gram.

\section{DATA FOR USE IN WIRE TABLES}

The data available from this investigation for use in connection with the preparation of wire tables are, in addition to the foregoing values for ( $\mathrm{I}$ ) the resistivity and (2) the temperature coefficient of copper, the following: (3) the difference, $2.7 \%$, between the conductivity of annealed and hard-drawn No. I 2 copper wire, together with a recognition of the general increase of this difference as the diameter of the wire decreases; (4) data on commercial hard-drawn aluminum, as follows:

ALUMINUM

Resistivity in ohms per meter-gram at $20^{\circ} \mathrm{C}=0.0763$

Micro-ohms per $\mathrm{cm}$ cube at $20^{\circ} \mathrm{C} \quad=2.828$

Density $\quad=2.70$

\section{THE EXPRESSION OF RESISTIVITY IN OHMS PER METER-GRAM}

The advantages of the expression of resistivity in terms of ohms per meter-gram may well be emphasized here. In specifications for purchase, or in expressing the results of conductivity measurements, the statement of the meter-gram resistivity avoids all questions of standard values which arise in connection with the percent conductivity. The use of the meter-gram basis corresponds most closely to the usual methods of making conductivity measurements in practice. There are cases, however, in which the cross-section is measured and not the mass, and hence the centimeter cube resistivity obtained. The difficulty of expression in terms of percent conductivity at once arises, that percent conductivity can be computed either from the meter-gram resistivity or the centimeter cube resistivity. If the density of the sample differs from the standard density, these two percent conductivities will not agree. This difficulty is made particularly clear by an inspection of the data on aluminum given above, page $\mathrm{I} 2 \mathrm{I}$. 
The extreme difference between the percent conductivities on the two bases makes manifest the absurdity of the extension of the idea of percent conductivity to metals of different density from that of copper, unless it be stated upon which basis the percent conductivity is reckoned. Thus, we may speak of the "percent conductivity on the meter-gram basis," and the "percent conductivity on the centimeter cube" basis. It is suggested that these terms be shortened, respectively, to the "mass percent conductivity" and the "volume percent conductivity," which terms should be readily understood. The various sources of possible confusion in the use of percent conductivity make it desirable that the actual restivity be stated. The meter-gram resistivity is preferable to the centimeter cube resistivity, because (I) the measurement of cross section in many cases is difficult and inaccurate; (2) the direct measurement of cross section is practically impossible for irregular shapes of cross section; (3) copper is sold by weight rather than by volume, and therefore the data of value to most users is given directly by the meter-gram resistivity.

\section{DESIRABILITY OF AN INTERNATIONAL STANDARD OF COPPER CONDUCTIVITY}

It is desired that the foregoing "data and suggestions shall not confuse existing practice, and it is not expected that they will make any change in the electrical engineering practice of this country until taken cognizance of by the American Institute of Electrical Engineers. Furthermore, an international agreement on copper standards is considered desirable. To ascertain whether this might be possible, the Bureau of Standards has had some preliminary correspondence with the national laboratories of Germany, England, France and Austria. Considerable interest was manifested in the matter. The use of the meter-gram basis was looked on with favor. In Germany and England the matter was referred to the national electrical engineering societies. No definite consideration has been as yet given by these bodies to the matter of international copper standards. Particularly in view of the fact that the vast bulk of the world's copper is mined and refined in the United States, it would seem appropriate for the American Institute of Electrical Engineers, through the International Electrotechnical Commission, to lead an attempt to 
secure agreement among the various engineering bodies. It is desired that none of the proposals in this paper should stand in the way of such an international agreement. It might seem desirable to base the international standard resistivity upon the purest copper that can be produced, instead of upon such an average of the commercial product as is given in this paper. However, difficulties arise in that direction. Finally, it is believed that the expression of conductivity on a percentage basis will be thoroughly satisfactory only after a definite international standard has been established.

\section{SUMMARY}

I. The various standard values in use for the resistivity and temperature coefficient of copper are given, and the need for the present investigation shown.

2. The means of making precise measurements of conductivity of wire samples is described.

3. The resistivities are given for 89 samples of commercial copper from 14 important refiners and wire manufacturers in this and other countries. The mean for annealed wires is:

Resistivity in ohms per meter-gram at $20^{\circ} \mathrm{C}=0.15292$

Percent conductivity

$$
=100.07 \%
$$

(Percent conductivity is computed on the basis of $100 \%$ conductivity corresponding to the standard resistivity, O.I $53022 \mathrm{ohm}$ per meter-gram at $20^{\circ} \mathrm{C}$.) The mean result of data furnished by a large wire manufacturing company, representing tests on more than IOO 000 ooo pounds of copper, is also given, viz, for annealed samples:

Resistivity in ohms per meter-gram at $20^{\circ} \mathrm{C}=0.15263$

Percent conductivity $=100.25 \%$

It is concluded that the best value to be assumed for the resistivity of annealed copper, in the preparation of wire tables and in the expression of percent conductivity, etc., is the previously used standard value, viz:

\section{$0.153022 \mathrm{ohm}$ per meter-gram at $20^{\circ} \mathrm{C}$.}

4. The conductivity of hard-drawn No. I 2 B. and S. wires was found to be less than the conductivity of annealed wires by a mean value of $2.7 \%$. The difference between the conductivity $58397^{\circ}-\mathrm{II} \longrightarrow 9$ 
of annealed and hard-drawn wires increases as the diameter of the wire decreases.

5. The lowest resistivity and highest conductivity found, for a hard-drawn wire, were:

Resistivity in ohms per meter-gram at $20^{\circ} \mathrm{C}=0.15386$

Percent conductivity $\quad=99.46 \%$

and for an annealed wire, were:

Resistivity in ohms per meter-gram at $20^{\circ} \mathrm{C}=0.15045$

Percent conductivity

$$
=101.71 \%
$$

6. Representative mean values for commercial hard-drawn aluminum were obtained, as follows:

Resistivity in ohms per meter-gram at $20^{\circ} \mathrm{C} \quad=0.0763$

Resistivity in micro-ohms per $\mathrm{cm}$ cube at $20^{\circ} \mathrm{C}=2.828$

Density

$$
=2.70
$$

7. The work on the temperature coefficient of resistance of copper, which is reported in another paper, ${ }^{6}$ was done upon samples included in this investigation. The temperature coefficient was found to be substantially proportional to the conductivity. This relation may be expressed thus: the change of resistivity per degree $\mathrm{C}$ is a constant for copper, independent of the temperature of reference and independent of the sample of copper; this constant is

$$
0.000598 \text { ohm per meter-gram. }
$$

8. The advantages of the expression of resistivity in ohms per meter-gram are stated.

9. The desirability of an international standard of copper conductivity is urged.

Washington, August r, i9io. 